\title{
ASTROS CAEN DEL CIELO, O DE CÓMO UN PUENTE NO PUEDE CRUZARSE UNA SOLA VEZ
}

\section{OSCAR GUARDIOLA-RIVERA}

Oscar Guardiola-Rivera es Senior Lecturer y Director del Programa de Derecho \& Justicia Política en la Escuela de Derecho, y miembro de la Junta Directiva del Instituto Birkbeck para las Humanidades del Birkbeck College, Univesidad de Londres (U.K.). Es autor de Being Against the World (Routledge/BLP, 2009a) y de What if Latin America Ruled the World?, que será publicado por Bloomsbury Press en 2010.

Artigo submetido em espanhol 


\section{HECATOMBE (ILL-FATED FALLING STARS)}

'Todo el mundo lo sabe. Esto está a punto de estallar'. Así comienza uno de los textos más controvertidos de la época reciente. Su título es L'insurrection qui vient (literalmente, La Insurrección que Viene, con todo lo que ello implica de invocación de la la hecatombe, y al tiempo, sugerencia de una forma específica del tiempo futuro). Fue publicado por una pequeña editorial radical Francesa a finales del 2007. Sus autores, a los que nadie aún conoce, se autodenominan 'El Comité Invisible'. En Noviembre 11 del 2008 fueron arrestados nueve individuos, la mayoría en la villa de Tarnac en la campiña Francesa, y acusados de 'asociación criminal para propósitos de actividad terrorista'. La acusación tenía que ver con su supuesta participación en actos de sabotaje a las redes eléctricas de las líneas de tren Francesas.

Aunque en contra de los nueve tan solo se ha presentado evidencia circunstancial y muy escasa, el Ministro del Interior Francés les asoció públicamente con la amenaza emergente de ultra-izquierdistas enmasacarados pertenecientes a un 'milieu autonomista', teniendo cuidado de particularizar este texto, que describió como un 'manual para el terrorismo', y cuya autoría se atribuye a los '9 de Tarnac'. Primero, quiero retar a las prensas Latinoamericanas, a Legis, a Eudeba, a Editorial Siglo del Hombre, al FCE, a Lumen Iuris, o Planeta, para que publiquen La Insurrección que Viene. No me hago ilusiones, pero lo hago con el fin de llevar a cabo un 'experimento mental' o en este caso práctico, no solo acerca del derecho a la libertad de expresión entre nosotros, sino mas bien acerca de nuestra supuesta sociedad y actitudes liberales, nuestro supuesto respeto a la ley, la constitución , y los derechos. La pregunta es: ¿hasta dónde llega nuestro supuestamente infranqueable compromiso con el pluralismo y la tolerancia? ¿Están nuestras intuiciones e institutciones demo-liberales dispuestas a no ceder ante la intolerancia cuando se trata de posiciones políticas que buscan transformar de manera radical el estado de cosas demo-liberal? O más bien, llegados a este punto, hay que concederle la razón al pensador Francés Alain Badiou, y a los miembros del Comité Invisible, cuando éstos afirman que además de la pluralidad tolerable de cuerpos y discursos, hay también el derecho al 'evento', es decir, las demandas y pretensiones de transformación radical más allá de los marcos establecidos como materia de verdad?

Querría iniciar un debate acerca de los límites de nuestras actitudes liberales y del ambiente político actual que sirve de marco (no solo entre nosotros) a cualquier discusión seria acerca de la constitución y los derechos. En este caso la Constitución Colombiana de 1991, o la Brasilera de transición, o cualquiera otra que hace parte de la ola reciente de constitucionalismo en la historia reciente de las Américas, de su jurisdicción, su aplicación, su realidad no meramente formal, y entonces, de su subsistencia. Pero entonces, también, se trata de una discusión acerca de nuestra subsistencia, la de aquellos de nosotros que militamos por la confirmación de las prescripciones constitucionales y de derechos en un futuro real autónomo, no en el meramente posible de los cálculos del riesgo y el gobierno de las poblaciones expuestas, tampoco como meras premisas para el trabajo especulativo más o menos racional de un grupo de jueces más o menos comprometidos con ella o con su sustitución por la figura del Ejecutivo decisor ${ }^{1}$-supuesta garantía de los valores universales, última defensa contra la hecatombe, príncipe retenedor del final de los tiempos y protector que denuncia públicamente la amenaza emergente de 'ultraizquierdistas y autonomistas enmasacarados' entre nosotros .

He propuesto un experimento mental 'algo más práctico'. Olviden el nombre propio de este o aquel Ejecutivo fuerte en la región. Podría ser, para el caso da más o menos lo mismo, el Ministro del Interior Francés, comentando acerca del caso de los 9 de Tarnac y del texto (al cual me he referido más arriba) que ha llegado a ser pieza clave en un caso jurídico y político cuyo argumento parece ser que el activismo político o el ejercicio activo de las libertades políticas - no otra cosa puede 
significar esta monstruosidad hechiza de gentes (periodistas, defensores de derechos humanos, académicos, miembros y miembras de comisiones auto-organizadas de la sociedad civil para poner fin a la 'guerra' por vía política y no puramente militar) convertidas en monstruosidades ellas mismas por parte de la gobernabilidad al ser tachadas como pertenecientes a un tal 'milieu ultraizquierdista y autonomista' - son razón suficiente para denunciar públicamente, apelar a la división anti-terrorista de la policía y la oficina central de inteligencia del Ministerio del Interior -el DCRI Francés, entre nosotros el infamous G3 o la tropa de élite.

Propongo este experimento con el fin de probar que en el caso presente, en Colombia como en Venezuela, en Brasil, en Francia y en otros lugares, discutir la subsistencia de la constitución y los derechos (como jurisdicción y técnica argumentativa de adjudicación, o cualquiera otra cosa, me interesa más esta 'otra cosa' como veremos mas adelante) es discutir el caso de una metástasis de la política de seguridad, doméstica y trans-nacional, aplicada ahora a cualquier y toda forma de actividad que importune el ejercicio del gobierno. A través de una tal política, mediante operaciones cuasilinguísticas que van de la mano con operaciones cuasi-militares, es posible hoy a nuestros más exaltados gobernantes, y a los ciudadanos cómodos con un estado de cosas reducido al mantenimiento de la 'ley y orden' con los cuales ellos se identifican -como los estudiantes de derechas de Nanterre que aplaudieron a la policía cuando esta expulsaba a sus compañeros de clase (cualquier parecido con la entrada de la policía a la Universidad Nacional de Colombia hace unas semanas, créanme, es no intencionada)- oponer al ciudadano (con derechos) el delincuente y el apátrida (sin ninguno) en una variación del tema proveniente de la época de la dictadura Brasileña de acuerdo con el cual 'contra la patria no hay derechos!'

El segundo objetivo de mi 'experimento práctico-mental' es mostrar que el ejercicio del gobierno tiene lugar hoy en dos niveles: (i) identificar a la multiplicidad de las masas y los pueblos (siempre en riesgo, o en trance de ser riesgo ellas mismas) con la incertidumbre acerca que viene; y (ii) realizar un obsesivo escrutinio del futuro en busca de signos de descontento social y novedad radical con el fin de cortar esos brotes antes de que florezcan o den fruto. En últimas, de lo que se trata hoy cuando hablamos de 'gobierno' (de las identidades y las poblaciones, incluido el gobierno de nosotros mismo como diría Michel Foucault) es de deferir el fin de los tiempos, detener el advenimiento del Anti-cristo para utilizar la terminología propia de la teología política, y en un sentido algo más secular, retener la llegada del momento en que las masas o el pueblo insurrecto se deshace de sus gobernantes o los des-elige. De manera más simple, la hipótesis que intento hacer evidente es la de un cambio sin precedentes de nuestra relación con la política en tanto que acción colectiva (y por lo tanto en tanto que poder constituyente). En adelante, dicha relación se articula en torno a 'una representación que pone la preocupación por la vida y la supervivencia en el centro del actuar político' (Abélès, 2008: 12) . Al contrario de una tradición que considera la convivencia, el estar juntos en comunidad (no-coercitiva) en diálogo (y que va de Kant hasta Arendt Y Rawls/Habermas) como el objetivo de los seres sociales, hoy es imperativo reconocer que 'el campo político se encuentra invadido por una duda lancinante en lo conciernente a la incertimbre y a las amenazas que contiene el porvenir' (ibid.) En una tal situación la incertidumbre, como dice el antropólogo Marc Abelès, 'despierta la angustia antropológica en relación con la perennidad de una humanidad percibida como precaria en razón de los peligros que ella genera' (ibid.).

\section{JUSTICIA Y DERECHOS EN LA SITUACIÓN ACTUAL: POR UNA RENO- VADA ACTITUD CRÍTICA}

Las ideas de justicia y de derecho que prevalecen en esta situación sólo adquieren sentido en la perspectiva del riesgo, su análisis, de los modelos probabilísticos de simulación y sujeción de la multiplicidad que representa el futuro real (y las masas) a la ley del Uno de la durabilidad, y de la

Hendu 1 (1): julho, 2010 
precaución como principio y en relación con el tema de la durabilidad-la persistencia de la comunidad supuestamente deseable en forma absolutamente necesaria, y su anverso, la consideración del conflicto como por necesidad indeseable. La política, y en tal sentido también la constitución política y la carta de derechos, son vistas entonces a la manera Humeana -lo que dicho sea de paso, nos conduce directo al post-kantismo que predomina en las conversaciones corrientes, otrora interesantes pero hoy francamente irrelevantes, acerca de filosofía política y del derecho, sea a través de Habermas, Rawls o Alexy, pero también, a la muy curiosa fusión entre monadología individualista, teodicea secularizada (Leibniz) y nihilismo (Nietzsche). Se dice: los humanos necesitan de la política y sus principios bien ordenados en una comunidad bien ordenada y estable de manera necesaria y absoluta, desde cuya perspectiva la decisión última (y 'difícil') es justificable, con el fin de producir y reproducirse; ésta tiene además la ventaja, bajo los así proclamados ideales de derecho y justicia, de promover la industria. Entramos entonces en un universo donde el futuro se piensa sobre la base de la probabilidad, ya no de la certidumbre del fin, como sucedía en las filosofías medievales o en las concepciones cíclicas pre-colombinas, y en el cual el cálculo de probabilidades permite una ciencia del pronóstico (cuya idea-fuerza consiste en suponer escasa variación de la situación dada en el futuro, lo que llevado al extremo lleva a la negación del tiempo) que constituye la herramienta indispensable para actuar sobre una situación política o económica.

Dicho de una vez, en este universo las ideas de justicia, derecho, y derechos se convierten en el último reducto del romanticismo historicista al configurarse alrededor de una forma de temporalidad (el futuro incierto, abierto o posible) repleta de figuras de necesidad: poblaciones monstruosas (en riesgo o en trance de convertirse en riesgo ellas mismas) y figuras capaces de anticipar el movimeinto futuro de la historia (y de esos 'monstruos'), y de ser necesario, suspenderlo y contenerlo(s). ${ }^{2}$

En este punto, al contemplar nuestra situación de entrapamiento en el presente de un mundo o un unverso sin porvenir, me parece relevante recuperar la crítica de ideologías en la reflexión sobre el derecho (los derechos, la constitución) y la política. Permítanme desarrollar esta afirmación que considero crucial con el fin de garantizar la buena salud de la disciplina jurídico-constitucinal y de la práctica política entre nosotros. A esta forma ideológica, circular y viciosa de catastrofismo se la puede identificar con una declaración apocalíptica de carácter oscurantista, ejemplificada como he sugerido antes por quien anuncia la hecatombe por venir con el fin de evitarla y en el proceso ofrecerse como representante sacrificial (víctima de numerosas y muy difíciles 'encrucijadas del alma') y príncipe retenedor del final de los tiempos.

Esto quiere decir que si en el escenario trans-nacional, el de la llamada 'globalización' que es un efecto y no la causa de una profunda mutación de nuestra relación con la política, la cual se articula en adelante 'en torno a una representación que pone la preocupación por la vida y la supervivencia en el centro del actuar político' (Abélès, 2008: 12) también lo es que en tal escenario el actor político que se supone necesario es el 'príncipe retenedor', el katechon de la teología política o el Ejecutivo decisor y fuerte de la teología política secularizada. En este escenario, ya se dijo, el problema de la convivencia (ser/estar-juntos) es reemplazado por el de la supervivencia -un campo político invadido por la duda, la vulnerabilidad, y la incertidumbre frente a las amenazas que contiene el porvenir, y por los cálculos y sacrificios considerados necesarios para garantizar la supervivencia y la protección contra las amenazas de la mayoría.

Esta mayoría no es por supuesto un simple dato, ni tampoco la mayoría procedimental de las operaciones democrático-formales; es fabricada como los factoides de los que habla Bruno Latour en el caso de las ciencias más y menos duras, de una manera específica. ${ }^{3}$ Lo anterior implica dos tareas fundamentales, que son metodológicas al tiempo que sustanciales: primero, explorar los procedimientos de fabricación de la mayoría y de otras figuras como formas naturales o históricas 
de necesidad real y absoluta en el campo político de la incertidumbre y la amenaza, lo que involucra de manera particular a las tele-tecnologías de comunicación, y de encuesta y tratamiento probabilístico o evaluación especulativa. Segundo, progresar hacia un pensamiento y una acción tras la cual organizarse para la supervivencia implique también organizarse de manera material para el ataque.

¿Cuál es el objetivo de este ataque? De una parte, el ataque es en contra de lo que Lewis R. Gordon llama 'la naturaleza cíclica del proceso disciplinar que consiste en moverse a través del naturalismo al historicismo y después a las evaluaciones del lenguaje como un agente independiente' (Gordon, 2006: 2). Como él explica, este ciclo fabrica, a través de la labor de las disciplinas -incluída la disciplina jurídica- una 'ilusión de permanencia' (ibid.). El objetivo de nuestro ataque es entonces, en últimas, esta ilusión o efecto de permanencia que en el sistema ius-político suele referirse mediante términos como 'estabilidad' o a travees del premio que se pone a la 'seguridad jurídica'. En este sentido al menos, nuestro ataque -es una ofensiva en común- se encuentra emparentado con la crítica de la metafísica, entendida esta última precisamente como la producción de figuras de necesidad y durabilidad absoluta desde lo que hay. De otra parte, entonces, lo que cabe recuperar en este punto es un sentido fuerte -diríase absoluto- de contingencia, en un sentido relativo pero que trasciende la biología y tiene que ver también con las ideas y las instituciones. Hablar de la contingencia radical de las ideas y las instituciones implica, en lo material y en la realidad vivida, contemplar el cambio y la transformación radicales como teniendo lugar (y no como meras posibilidades), levantarse en contra del gobierno de la opinión sobre la verdad y la evidencia, y en general en contra de todo aquello que ha sido elevado desde el espíritu en contra de la realidad. Lo anterior implica también una obligación: estar dispuestos a enfrentar la verdad en nuestro interior como un valor de verdad afuera. Y como bien sabemos, este tipo de verdades son mucho más dificiles de soportar. Hacer del pensamiento una actividad vivida con frecuencia requiere actos de disrupción y la ocurrencia de eventos decisivos en sus consecuencias (Gordon, 2006: 6-7).

En este punto cabe notar dos cosas: de un lado, que estamos enfrentados en últimas a formas bien conocidas de la metafísica dogmática. Del otro, el concurso crucial de las tecnologías de temporalización virtual (tele-medios, surveys, simulaciones probablísticas) en estos procedimientos de formación necesitarianista y dogmática que son hoy la 'ontología' (en verdad, una teodicea secularizada) de base del derecho. ¿Cuál es el punto? Por lo pronto sugerir que el apocalipticismo oscurantista de nuestra época ya no apela a la visión de un cielo firme (cuyas formas matemáticas traducirían una legislación divina/natural y perdurable, aplicable guardadas las proporciones a los asuntos humanos); mas bien, se conforma con la visión de las estrellas en vídeo durante horas y horas como en la película Metrópolis de Fritz Lang.

En la situación actual se trata -en derecho, en política, y en la vida social- de trasponer a una pantalla, y por lo tanto al mundo sub-lunar de la economía, las noticias, o la supervivencia política en la historia, el procedimiento mediante el cual se supone posible elegir el mejor de todos los mundos posibles y cuyas formas matemático-probabilísticas traducirían una legislación natural y necesaria pero inmanente y limitada a los asuntos humanos. He aquí el secreto revelado de una teodicea y un ius-naturalismo pos-modernos (supuestamente evaluativos en un mundo sin valores o con valores plurales) predominantes hoy y que reemplazan a la constitución (en el sentido de la reconstrucción constante de los objetos públicos, el hacer común del Común) sin suspenderla in toto. En apariencia, tan sólo bastarâ al decisor posmoderno que busca sustituírse a sí mismo por la consstitución y en el camino disolver al pueblo para darse uno nuevo, dócil y gobernable, hecho a su medida y transmutado en mera ‘opinión' (debe recordarse que al menos desde Sócrates y Platón si contra algo lucha la filosofía, si algo ella ataca es, precisamente, la opinión), conectar este cuerpo especulativo, dogmático y virtual -este aparataje concreto de tele-medios y formas simuladas probables- al espíritu inerte de la constitución y los derechos. 
Afirmo que resulta crucial el papel que pueda jugar una renovada crítica de ideologías en esta situación. Como se sabe, la ideología no puede ser identificada de manera ingenua con cualquier variedad de representación artificiosa o ilusoria, sino que mas bien se debe entender por ella toda forma de pseudo-racionalidad cuyo objeto sea establecer que lo que existe de hecho (como un factoide, por ejemplo una simulación probable o el estado de la opinión y su líder protector) existe también de manera necesaria. La crítica de ideologías, que consiste en demostrar el que una situación presentada como necesaria e inevitable es en realidad contingente, se encuentra en tal sentido relacionada de manera íntima a la crítica de la metafísica, entendida esta última, ya se ha sugerido, como la fabricación de formas, entidades o seres necesarios de manera absoluta.

En nuestra época el papel de tales figuras es atrapar, retener, deferir, y si es el caso detener o contener el tiempo (el futuro incierto identificado con la potencia activa de las masas; en el pasado se trataba de retener y contener todo el espacio de manera absoluta que es lo que de manera ususal hemos entendido por colonialidad e imperio). Resulta notable, sin embargo, que hoy como ayer tales figuras apelen a la metafísica más dogmática de otra era, la que dice que este Dios existe con necesidad absoluta, y que este Dios que existe con necesidad absoluta nos mantiene -a nosotros o al líder- con vida (de lo cual se sigue que nuestra vida comunitaria o la del líder participan de esa necesidad absoluta) tanto como a la aparentemente más refinada de nuestra era que habla de la necesidad que nos imponen los tiempos.

Una crítica de ideologías así entendida no se desliza al relativismo pluralista (todo es igualmente necesario, todo tiene razón y sucede por una razón) ni busca restaurar una era del pensamiento dogmático a la que no parece posible ni deseable regresar. En cambio, opone al apocalipticismo oscurantista uno esclarecedor, similar al don de la profecía en lo que hace a su interés por la reducción a la práctica de imágenes virtuales del futuro y cercana a la concepción que de la constitución y de la soberanía popular (o el poder constituyente) han tenido los revolucionarios de todas las épocas, como St. George Tucker o Thomas Jefferson en el caso de la revolución Americana, y Toussaint L'Overture en de la Haitiana, tan decisiva para entender los eventos de Francia y de las Américas en el largo siglo XVIII .

Empero, al contrario de nuestros forecasts expertos, la crítica que propongo descubre en la necesidad de la contingencia una necesidad absoluta que no establece forma alguna o entidad absolutamente necesaria. Se trata de rehusarse a aceptar la afirmación de acuerdo con la cual 'todo tiene razón', proponer y proponerse o prescribir en forma militante la realización de una imagen futura deseable (un mundo igualitario, no sometido por el miedo y la crisis continua o la supuesta necesidad del orden y la perdurabilidad de la comunidad 'perfecta' o 'perfectible') por improbable que esta parezca, y al tiempo reconocer que ninguna necesidad absoluta subtiende esa prescripción o su reducción a la práctica, que no hay leyes ni potencias inherentes al curso de la historia que dirigen esta última y que al realizarse la culminen. Se trata entonces de pensar el futuro y la realidad bajo el modelo de la infinitud, no como potencia o virtualidad posible sino como realidad actual con todo y sus paradojas.

El tipo de preguntas que corresponde hacerse es más o menos el siguiente: ¿De qué clase de necesidad se trata? ¿A qué tipo de incertidumbre obedece la construcción de esta particular figura de necesidad? ¿En qué forma se enlazan la incertidumbre respecto de una catástrofe posible o el riesgo de que dicha catástrofe ocurra, la decisión que se supone puede deferirla, y la seguridad? ¿Cómo pasa este enlazamiento al lenguaje constitucional del Ejecutivo fuerte -el decisor que declara el estado de excepción? ¿Basta el paradigma del estado de excepción o emergencia, la suspensión de la vigencia normal de los derechos y la ley, para enmarcar esta situación? ¿O más bien nos es necesario desarrollar posturas más robustas en lo que hace al imperio de la ley, la constitución, y el poder estatal? ¿Cuál sería, llegados a este punto, el sentido de una demanda por lo político y la acción política radicalmente innovadora? ¿Es posible hablar aún de innovación radical en política? 
¿O hemos de tirar al niño, la innovación política y la urgencia escatológica en relación con el estado y la situación presente, junto con el agua, el desencanto y el resentimiento revolucionario y contrarevolucionario?

\section{NO SE PUEDE CRUZAR UN PUENTE TAN SÓLO UNA VEZ}

No voy a responder a todos estos interrogantes. Esa es la tarea de la filosofía política y la teoría jurídica (de la insurrección) que viene. Pero sí quiero sugerir algunos caminos. Para ello debo proponer un segundo 'experimento mental'. Imaginen una ciudad dividida por un rio, Könisberg por ejemplo. Las dos mitades del centro de la ciudad están comunicadas por siete puentes. A ustedes le corresponden recorrer todo el centro de la ciudad cruzando cada puente tan solo una vez. ¿Cómo pueden hacerlo?

Propongo este experimento porque me parece que guarda relación con dos intentos que considero muy importantes en teoría jurídica contemporánea, ejemplos de la crítica de los ideologismos que predominan en nuestras concepciones presentes acerca de las relaciones entre sociedad y derecho, y política y derecho o derechos. Son importantes en el sentido de abrir la teoría jurídica de su particularidad a una generalidad muchísimo más interesante y relevante. En Estados Unidos la General Jurisprudence of Law and Society de Brian Z. Tamanaha (2001) y en América Latina la Teoría Impura del Derecho de Diego López Medina (2004). Tengo la suerte de contar con ambos como amigos y pienso que la elegancia e influencia de sus teorizaciones es innegable. Sin embargo, llegados a este punto, no me queda otra alternativa que apartarme de la manera de concebir las relaciones entre la teoría jurídica general y la teoría jurídica particular que ambos representan, de manera diversa pero relacionada. Ello por razones histórico-filosóficas. La primera razón, que resultará quizás obvia a quienes me hallan seguido sin dormirse hasta este punto del ensayo, es que aunque se trata de lecturas sumamente elegantes es bien posible que hayan dejado de ser interesantes. Ya se ha dicho, lo interesante hoy no es el enfrentamiento entre la particularidad y la universalidad sino el choque de universos y generalidades (entre el capitalismo financiero global -el par seguridad y desarrollo-, y lo social o el común -incluyendo el 'social' del 'estado social' del constitucionalismo de los derechos en Latinoamérica desde los noventas).

En este sentido, me parece que las metáforas de viaje, ecos lejanos de la visión medio-Platónica del mundo, no resultan aptas o eficaces para hablar de choques, luchas, ataque y enfrentamientos. En el mejor de los casos, tan sólo pueden hablar de acción (o movimiento, o cambio, o reforma) y resistencia, o como suelen decir estos teóricos more literario, de producción original y recepción o copia. Ahora bien, el problema con la mera resistencia es que las más de las veces suele ser reactiva, si es que no reaccionaria.

La segunda razón aparecerá menos obvia, aunque ha estado en operación desde el comienzo de este ensayo: el problema con el modelo de la reproducción analógica, el modelo de la difusión o el viaje desde los centros de producción original a los de copia reactiva es que, aún en la versión más moderna que utilizan los autores a los que me he referido, la copia es todavía presa de una referencia única que si bien no es ya mas el original en el sentido más fuerte, más platonizante, sí constituye al menos una matriz. La presunción que continúa operando en estas elegantes teorizaciones concierne entonces a la primacía ontológica de la unidad -la supuesta unidad de la producción original, en cuya fabricación no habríamos participado- sobre la multiplicidad de las copias y recepciones. Ello a pesar de sus compromisos pluralistas y sus preocupaciones, muy justificadas por demás, con los temas del contexto y la perspectiva, y de la complejidad de las identidades y los itinerarios. ${ }^{4}$

En la variación pluralista de la primacía del uno sobre lo múltiple, o bien la verdad es singular y 
universal antes que concreta o específica, o existe una pluralidad de verdades ninguna de las cuales puede pretender más que una extensión espacial y temporal mas o menos modesta. Deberíamos entonces cuidarnos de no traer con demasiada rapidez las ideas y formas jurídicas de los centros de producción universal a los de recepción plural, habida cuenta de la singularidad de estos últimos. Esta afirmación que en principio parece saludable, mantiene la distancia analógica entre centros y periferias -entre universo y pluralidad- y de ello concluye la disfuncionalidad (reactiva o menos creativa) de los préstamos, y el autoritarismo de los universales de producción sin detenerse a pensar que un universal es precisamente tal solamente en la medida en que una concreción decisiva lo afecta, lo fragmenta, y la muestra entonces siempre y en todo caso diviso.

Quienes así piensan parecen asumir que mientras el 'universo' sugiere de manera casi inmediata una serie de compromisos relacionados con ciertas formas de racionalidad y notas esenciales compartidas (que irían desde el esencialismo de los derechos humanos hasta el carácter 'global' del ambiente o la economía) el pluriverso puede en cambio reclamar la posición democrática de avanzada. Se supone que existe algo autoritario de manera más o menos obvia en la idea de un universo, a pesar de o debido a sus pretensiones de verificación no social u experiencial-objetiva, mientras que el pluri-verso por necesidad debe poner su fe en formas de democracia y pragamatismo político con el fin de elevarse sobre y en contra del mundo caótico del naturalismo, el formalismo, el relativismo y la inacción.

Los 'muchos' democráticos aparecen entonces obviamente preferibles al 'uno' autoritario, aún si a veces sea necesario hacer a un lado el tortuoso y lento camino del debido proceso y las formas del derecho y la democracia a través de la pretensión de saber que sea lo mejor. Dicha pretensión se presenta las más de las veces en términos pragmáticos: o bien como el resultado de un análisis de las consecuencias más o menos directas en términos de una función dada de maximización (p. e. el 'bien común', su capacidad de funcionar bien en un contexto de recibo, o una medida de eficiencia) o a través del cálculo de costos y beneficios. Nótese además que esta última, o su pariente próximo, el análisis del riesgo y las formas de prevención, no dista tanto como se cree de la primera. ${ }^{5}$

No estoy afirmando que ciertos autores en particular, a los que me he referido antes por ejemplo, se encuentren comprometidos con estas formas más o menos glorificadas del análisis de costo-beneficio en sus aproximaciones a la teoría jurídica y política. Es bien posible que las rechacen, o que opongan a ellas (por ejemplo, en la figura de los trabajos del juez Posner en los Estados Unidos) formas de aproximación sociológica o histórico-institucional (las de Douglass North, por ejemplo). Mi contención es que la teoría histórico-social que subtiende la teorización jurídica y la filosofía política entre nosotros, aún la más sofisticada que atiende a los préstamos y trasplantes singularizando los contextos y trayectos de recepción como puentes de una sola vía, tiende a reproducir una geometría familiar y una matemática mas bien convencional.

La matemática de esta teoría social distribuye lo que cuenta en el mundo en términos del uno y los muchos. Su geometría está marcada, de manera similar, por un 'arriba' y un 'abajo', o un centro de cuyas producciones no participamos y una periferia tan sólo receptiva, así la recepción sea reactiva. Así como el pluralismo de los muchos, el de los contextos singulares de recepción por ejemplo, es preferible al autoritarismo del unitario formalismo jurídico centrista, 'abajo' es donde está la acción real mientras que 'arriba' están lo abstracto, lo irrelevante, lo hegemónico y lo ilusorio.

Tales coordenadas pueden aplicarse además a la producción y distribución de conocimientos, el conocimiento jurídico-político por ejemplo; pero también se las puede co-relacionar a otros términos binarios como Norte/Sur, centro/periferia, mente/cuerpo, masculino/femenino, y a la distribución 
de las relaciones de poder que en general se asocia a estos pares binarios. Y dado que uno de los propósitos de la teoría histórico-social es mostrar el carácter artificial e injusto de estas divisiones, al contrario de los filósofos atrapados en la caverna de Platón la teoría y las ciencias históricosociales se refieren a un mundo de experiencia y conocimiento distribuído de manera desigual. Sus esfuerzos empíricos, primero, y solamente después teóricos, se encuentran entonces dirigidos a involucrarse con el mundo de 'abajo' que es experimentado y conocido de manera singular. Así las cosas, esta teorización no quiere tener nada que ver con universales o formas más allá de las condiciones de experiencia posible (por ejemplo la contingencia, entendida como condición previa sin-Ser de todo aquello que viene al Ser).

Los filósofos críticos de hoy solemos hacernos dos preguntas frente a este estado de la cuestión. En primer lugar: ¿qué sucede con la legitimidad de una protesta (siempre perif'rica, sea en América Latina o en Europa) cuando las condiciones de desigualdad, injusticia, opresión o explotación que la animan son entendidas en términos de 'experiencia', 'recepción', 'des-conocimiento', 'creencia', ‘afecto' o ‘percepción' singulares? (Gordon, 2007: 6). En segundo lugar: ¿qué sucede si, a pesar de lo que hayamos ganado gracias a la renuncia de la teoría histórico-social a las versiones específicas universales y la verdad, resulta que la insistencia en verdades plurales y recepciones múltiples respecto de las cuales no puede decirse que su valencia sea opresiva o emancipatoria, es al mismo tiempo filosóficamente problemática y políticamente paralizante?

Ejemplos de este tipo de cuestionamiento pueden encontrarse por ejemplo en los trabajos de la filósofa Holandesa Annemarie Mol acerca de las ciencias médicas, los de Susan Haack y Valerie Kerruish (una Australiana en Alemania) en lógica, los del teórico jurídico Británico de origen Sudanés William Twining en Londres (en diálogo con las 'voces sureñas' de Upendra Baxi, Yash Ghai, Francis Deng, Abdulahi An'naim y la mía, entre otras), los del fenomenólogo Jamaiquino Lewis R. Gordon quien trabaja en los Estados Unidos, y los de la filósofa y teórica jurídica critica Americana Drucilla Cornell quien trabaja en Sudáfrica, entre otros.

Combinando la abstracción especulativa, la metacrítica de la razón, y el análisis, con el trabajo de campo etnográfico, la observación participante, las formas activas de 'des-aprendizaje' y 'reexistencia' (decolonial unlearning, teleological suspension, y sociologies o phenomenologies of (in)existence, en los casos de Lewis Gordon y De Boa de Sousa Santos, ${ }^{6}$ entre otros) estos investigadores nos muestran de qué manera las prácticas que tienen lugar en los lugares de cuidado (en el sentido médico y neo-humanitarianista o biopolítico), confrontación, o solución de conflictos, distan mucho de conformar un todo coherente, pero pueden ser y son en efecto ensambladas para conformar cuerpos funcionales de conocimiento que pueden ser utilizados para hallar buenos tratamientos o formas políticas mejores y más justas, y lugares, espacios reales, en los cuales eventos de este tipo ocurren y cuyas consecuencias los validan en forma decisiva a los ojos de sujetos que llegan a la existencia como portadores de verdad y no tan solo de creencia o reacción a lo difundido (la Bolivia descrita y actualizada por Álvaro García Linera y Sylvia Rivera Cusicanqui como lugar de producciónius-política, para dar tan solo un ejemplo).

Se trata por supuesto de una aproximación normativa, y ya lo he dicho, militante, interesada en mejores conocimientos y en transformaciones reales y decisivas. Pero una que no se satisface con el reconocimiento experiencial de la pluralidad, con la capacidad decisional y el pragmatismo de un consumidor o de un sujeto singular (en las versiones más críticas) o excepcional dado (en las versiones menos críticas), o aún con el diálogo agónico (convertido en la teoría y la práctica de hoy en ambiente y condición sine qua non de la democracia, o de la globalización pluralista) sino más bien se compromete con procedimientos, acciones prácticas, y saberes (expertises) involucrados en el diseño, investigación, y desarrollo de medios prácticos (o 'puros medios', si se me permite citar a Benjamin en este contexto) para seguir adelante con vidas que son complejas desde el comienzo y 
siempre no finalizadas.

Desde esta perspectiva pienso que resulta más apropiado hablar de multiplicidad que de pluralidad. La pluralidad se refiere a los muchos y a la referencia retroactiva de esos muchos o su reducción a la unidad a través de un debido proceso, de la misma manera en que las muchas copias se refieren al original o los contextos de recepción a lo recibido o 'tomado a préstamo' de contextos de producción sin participación, para utilizar la jerga de los difusionismos jurídicos, por ejemplo. Otra instancia de pluralismo, muchísimo menos crítica que la anterior, es aquella que en el discurso y las políticas del desarrollismo económico plantea la existencia de varias velocidades del desarrollo -del sur en comparación al norte, de un sector económico frente a otro en una economía en desarrollo- en una misma dirección, de manera similar a como en el derecho internacional, el comparativismo, y las relaciones internacionales se habla de 'orden y orientación' en el sentido dado al término por Carl Schmitt. La multiplicidad, en cambio, debe entenderse en términos de 'auto-diferenciación infinita' de la misma manera en que la topología y la matemática de conjuntos postula el infinito; un infinito que se mueve, como Lucrecio lo habría puesto en la antigüedad, 'sin límite y en todas direcciones.'

Dos corolarios se siguen del descubrimiento de este tipo de multiplicidad: primero, que cuando se trata de la multiplicidad no estamos simplemente frente a un objeto de la experiencia. La multiplicidad no es tan solo el correlato de nuestras facultades subjetivas de unificación o cuenta (incluída la especulación probablística, el establecimiento de 'seguridades jurídicas' por indiferencia subjetiva en procesos de adjudicación cautelosa, o los análisis bajo principio de precaución). Segundo, de lo que se trata es de evitar reintroducir la reducción a la unidad allí donde la ley de la multiplicidad comienza a parecer inaplicable. En derecho y en política ello significa no hablar más acerca 'el origen' (como 'contexto de producción', por ejemplo), 'el padre y su ley', 'la comunidad' por él fundada en su palabra reguladora, 'el pueblo' si se lo entiende en un sentido similar, 'el estadonación', o sus derivados, tales como el 'estado de derecho' o el 'estado de...' cualquier otra cosa, como si el procedimiento de unificación (por ejemplo, la opinión o la síntesis sobre los fines de una comunidad dada) pudiese reducir todo lo que sucede a una instancia decisoria o creativa, como por ejemplo, en las versiones más reaccionarias, un pueblo-electorado (el pueblo 'disuelto' y recompuesto al que me he referido antes) identificado de manera más o menos unánime con su líder-decisor.

Sobre esto, lo mínimo que hay que decir es que toda unanimidad es por definición unanimidadmenos-uno, el uno que es mostrado como el 'enemigo' y límite externo del pueblo unánimemente unido alrededor de su jefe. Este procedimiento, que reintroduce el poder del uno al nivel de lo que ocurre, puede encontrarse por ejemplo en el paroxismo de la política Colombiana de indentificación total con el líder o 'el patrón', como dice el joven y muy talentoso teórico jurídico Juan Felipe García, ${ }^{7}$ mediante la sustracción de un elemento por fuera del conjunto como el enemigo total de ese conjunto. En ese caso la unidad de la que hablamos no es derivativa sino primaria, no el resultado de una operación (la sustracción del enemigo) sino una fuerza constitutiva (del líder versus la constitución). No debería sorprender entonces, que en tales casos, el líder termine reemplazando a la constitución. Expulsado del nivel metafísico, el uno regresa aquí en el nivel pragmático: disfrazado como un acto 'excepcional' o una 'experiencia decisiva' que determina el nuevo espacio constituído y el futuro posible.

Otra forma del regreso de lo uno a la teoría social y jurídica es el caso de la distribución del conocimiento jurídico a través del globo en términos de 'experiencias singulares' o periféricas de una matriz central, en contextos de recepción particulares. Nótese que estar en posesión de una matriz -como en el caso de un negativo fotográfico-implica tener el control sobre las copias, aún si la experiencia de la copia resulta decisiva para quienes la experimentan de una cierta manera en contextos singulares. Valga decir, tras proponer esta alegoría entre el derecho comparado y la industria del cine, a fin de cuentas ambas son industrias ideológicas, que esta es una de las razones por las 
cuales la industria del cine en Hollywood es tan reacia a las tecnologías digitales; se trata de controlar no la producción sino la distribución, de imponer puentes que sólo puedan ser cruzados una vez. Dicho sea de paso, este fue un punto central en la reciente huelga de escritores en Tinseltown. Quizás los historiadores del futuro digan que esta fue la primera huelga significativa de la era digital y la sociedad de la información. La posición de los huelguistas -análoga a la respuesta al experimento mental sobre los siete puentes de Konisberg- era que resulta imposible cruzar un puente tan sólo una vez. Las formas de distribución digital, que trabajan con $\mathrm{n}$ dimensiones y no tan solo con puntos y líneas, no lo permiten. Por tal razón la industria ideológica, sea la del cine o la de la implantación de modelos jurídicos como parte de las industrias pos-modernas de 'ayuda para el desarrollo' en la fusión en curso entre seguridad y desarrollo capitalista, continúa aplicando normas propias de la era analógica (por ejemplo los trade related intellectual property rights, o el pivote de los derechos entre liberalismo político y demandas sociales contenidas, o las quizá menos recientes formas de colonialidad del poder de que hablasen el sociólogo Peruano Aníbal Quijano y el historiador y economista político Immanuel Wallerstein) a fuerzas de producción de espacio y temporalidad digital (por ejemplo, la red, en el caso de movimientos sociales y sus demandas universales).

Es cierto que pueden extraerse un número plural de copias a partir de una matriz (es decir, la recepción puede ser re-activa) pero la fotografía obtenida mediante este procedimiento no traduce de manera exacta la información proveniente de la matriz. El viejo modelo analógico se re-introduce de esta manera, por la puerta de atrás, en las mejores teorizaciones jurídicas contemporáneas acerca de los viajes del derecho en la era de la globalización. De allí que estos autores utilicen en sus elaboraciones teóricas criterios pragmáticos de medición (Tamanaha, 2001) o pragmático-valorativos (tomados por ejemplo de la teoría literaria comprometida con la construcción de cánones, tal es el caso del misreading Bloomiano que utiliza López) de una sola vía. De esta manera se cumple la norma de todos los sistemas de reproducción analógica: que se asista a una pérdida de información, tanto más significativa cuanto mayor sea la acumulación de generaciones (nótese que el más es aquí tanto espacial como temporal; un cronotopo de adición por completo ajeno a las complejidades matemáticas modernas). Para seguir en teoría literaria, estamos ante la tesis Borgiana del mal infinito.

Ahora bien, el punto de una 'infinitud mala' es que la relación matriz-copia perpetúa, así ello ocurra de manera inconsciente, la relación de expansión de adulto a menor (del más a lo menos) que reposa en el corazón de la estructura ideológica moderno-colonial. De manera que quedamos condenados, sea como fuere, aquí en la periferia, a la particularidad, el empoderamiento progresivo, y la 'minoría de edad' teórica y práctica; pues la generalidad teórica como la mayoría de edad es asunto de los centros de producción, de las matrices. Se trata entonces, en último término, de una concepción occidentalista o centrista, poco útil para explicar el multicentrismo jurídico pace Tamanaha. O bien, se trata de una forma de singularismo cultural, aún si ello ocurre a espaldas de la intención de sus autores. Lo que parece escapar a estas lecturas de viaje -el viaje de los conceptos, su 'triunfo' en contextos de recepción extraños- es la siguiente alternativa: que lo que haya sido y será inventado (considerar la dimensión futura como real, y no tan solo como posible, es crucial en este punto del argumento) sea una nueva composición del mundo, que implica la modificación concreta de aquellos componentes que habían proclamado la necesidad de excluír lo que finalmente llegan a aceptar (Stengers, 2009: 18; Escobar, 2008: 296-8).

Si uno quiere hacerse al lado de esos otros que desde 'abajo', en luchas reales antes que abstractas, denuncian aquello que les excluye como un abuso de poder, habría que recordar que el resultado de tales luchas no puede ser definido por el pensamiento especulativo y calculador -que aquí he denominado para bien o para mal analógico- porque el resultado victorioso no consistirá tan solo en la suspensión de una arbitrariedad abusiva. Lo que será inventado, ya se ha dicho, es una nueva composición del mundo en la cual la necesidad de lo excluído se muestra por completo contingente. Lo que aquí se sugiere es una conexión entre moralidad (o derecho y politica) y experimentación a 
gran escala, la construcción de conexiones o puentes entre lo que era mutuamente exclusivo, cuyos resultados tan solo pueden ser juzgados a posteriori.

En un momento de bella inspiración, el sociólogo y teórico jurídico Boaventura de Sousa Santos ha inventado el término 'teoría de retaguardia' para referirse a esta configuración del pensamiento y de la acción (Santos: 2009). Tal conexión no es relativista. No se trata de que las colectividades involucradas en el trabajo de innovación cedan a toda otra demanda que las confronte en el entendido relativista de que ninguna demanda debería imponer nada sobre nadie. En tal caso no habría ganancia alguna, tan solo tristeza y renuncia. Se trata, antes bien, de que innovar y transformar son materia de luchas, involucradas en la composición o construcción artificial del mundo y sus sistemas heterónomos, como los derechos y las constituciones por ejemplo, antes que materia de conocimientos que por definición siempre son relativos a un estado, en tiempo y espacio, de esa composición.

Como en el caso de la evolución biológica, y sería mejor proponer analogías entre la teorización jurídico-política y la biología que continuar la una vez pero ya no liberadora experiencia de los préstamos entre derecho y narrativas o análisis económico-literarios, lo que está de por medio no es la selección de los mejor adaptados, la victoria de unos y la eliminación de otros. Lo que está de por medio es 'la invención de nuevos modos de composición, que maximizen las posibilidades para la co-existencia de aquellos que en cada época parecen destinados a excluírse' (Stengers, 2009: 18). Ahora bien, dicha coexistencia no tiene por qué ser pacífica. Quienes están 'destinados a la exclusión' ya no cuentan en este mundo, en la situación presente; por lo tanto su re-aparición - que reinventa el mundo- no puede ser sino violenta (Guardiola-Rivera \& Coombs, 2009). De una parte su sola existencia, que de por sí no tiene nada que ver con los 'medios' usados en la lucha, ya es violenta para aquellos que los perciben destinados a la exclusión de manera necesaria. De la otra, la innovación político-jurídica real tiene lugar en el campo de lo improbable -antes que en el de lo posible-, es decir, como la toma de aquello que no ha sido ni será concedido de manera voluntaria. En tal sentido, es violenta.

Dicho de otra forma, lo que motiva la historia colectiva, global, no es una fuerza o unidad de orden y dirección inmanente o externa (llámesela como se la llame: 'providencia', 'nuevas ideas', 'el propósito de la razón', la 'armonía social' o la 'mano invisible'); es lo que una organización social excluye y que retorna como un fantasma, y que de cuando en cuando da lugar a sujetos hablantes capaces de declarar o prescribir una prueba, un experimento colectivo capaz de producir -y aquí, como en biología, se trata siempre de un juicio retroactivo- un mundo mejor. ${ }^{8}$

En la historia de los viajes globales del derecho y la política que he llamado 'analógica' no se explica la interconectividad global sino que se asume la reproducción del estado-capitalismo (el ente necesario creado por la ideología económico-jurídica) desde Europa hacia el exterior, incluyendo, bien sea a mediados del diecinueve o el veinte, todo el mundo. En la primera versión de esta historia, lo que habría permitido tal reproducción es la difusión de las instituciones occidentales, y de manera singular, aquellas relativas al establecimiento, defensa y protección de los derechos de propiedad sobre las cosas y el intercambio, de manera tal que se permita y estimule el crecimiento de los mercados. El gobierno de las leyes y los derechos habría surgido, se nos dice, como solución al problema de los altos costes transactivos (el costo de proteger, fijar, hacer exigibles, usar, derivar provecho, intercambiar) minimizados a través de la estabilidad institucional, y en particular la habilidad del estado para hacer exigibles los contratos. En otra versión de la misma historia se nos dice que son las relaciones capitalistas de producción las que surgen primero, trayendo consigo en un momento posterior instituciones de soporte y fijación.

Esta historia, en cualquiera de sus dos versiones, es criticable como un discurso singularizante, 
, analógico, que asume la prioridad del uno a pesar de sus declaraciones pluralistas: en efecto, representa a las instituciones occidentales como las únicas capaces de facilitar el crecimiento económico. ¿Cómo explicar entonces el ascenso actual de China? 'Ah', responderían los críticos conservaduristas, 'por su adopción de los modelos occidentales'. Frente a esta afirmación cabe observar que resulta por lo menos curioso reconocer el hecho que solamente hasta ahora China se encuentra en importando modelos contractuales y comerciales, especialmente desde Alemania. Es decir, después de que su ascenso sea un hecho cumplido. Ahí están además las muy rigurosas investigaciones de Giovanni Arrighi acerca de los caminos divergentes del desarrollo. Su punto es que hay que volver a cruzar el puente, esta vez en dirección a China, y yo añadiría, en dirección a la 'nueva' América Latina (Guardiola-Rivera, 2010): en ello, antes que suponer una convergencia que no ha existido ni existirá jamás, consiste descubrir a Adam Smith en Beijing, o a Raúl Prebisch en Londres o Nueva York.

Las alternativas propuestas hasta ahora a esta explicación dominante tienen sus propios problemas. Dos alternativas han sido las más usuales: primero, definir una pluralidad de modos de producción, lo que permitiría postular la existencia de regiones que devienen capitalistas en un sentido y permanecen sin serlo en otro. Con todo, el fin de esta historia, la colonización de la economía mundial por el capitalismo durante el largo siglo diecinueve, resulta familiar en demasía. Se trata de una mera variación sobre el mismo tema de la convergencia. Esta es la alternativa que desarrolla por ejempo Eric Wolf en su Europe and the people without history. Más aún, la cuestión real, como ha observado hace ya varios años el teórico político Ernesto Laclau, tiene que ver con elaborar los términos de la articulación que permite enlazar los diferentes modos de producción. Una vez hecho lo anterior, aparece una cuestión más interesante: ¿Estamos frente a una convergencia de lo diverso en el universo original, o más bien, frente a un nuevo Universo?

Una segunda propuesta, relacionada aunque diferente, consiste en postular que las instituciones son secundarias a la economía en el sentido en que, en la larga distancia, las primeras simplemente no importan pues ceden ante la segunda (en particular, frente a las relaciones comerciales). En este orden de ideas, André Gunder Frank por ejemplo ha argumentado que las instituciones 'occidentales' no eran en verdad definitivas para el desarrollo de la economía global. Esta economía habría emergido mucho antes de lo que suele denominarse un orden capitalista global. Los problemas no se dejan esperar: de un lado el argumento lleva directo a la postulación de 'pre-condiciones necesarias' para el crecimiento capitalista. Sin embargo este tipo de argumentos no permitiría establecer las razones por las cuales el mercado se estabiliza primero en Europa que en China, a pesar de que -como el propio Gunder Frank observa, siguiendo a Smith- las instituciones de esta última eran tan favorables al mercado como las de la primera e igualmente racionales. Además, esta argumentación nos deja sin herramientas para entender las relaciones entre institucionalidad político-jurídica y economía. En esta narrativa la forma estado es una respuesta a tendencias económicas, la economía mundial estaba conectada desde una etapa muy temprana y siguió estándolo, así su centro se haya desplazado desde Beijing y Bagdad en algún momento hacia 1800.

La única pregunta relevante acerca de las instituciones jurídicas en este contexto sería, una vez más, la del transplante, es decir, si los estados del Este adoptaron, como los estados Europeos, un conjunto de medidas a través de las cuales se hizo posible el crecimiento. Estas narrativa no postula sin embargo la cuestión más interesante: ¿Cómo llegó ‘el estado-derecho’ a convertirse en una entidad respecto de la cual la cuestión de los transplantes puede debatirse, en primer lugar? ¿Fueron los incrementos en el volumen del comercio los que estimularon la formación de ese ente en todas partes? ¿O más bien, no implica ello que desde el comienzo la expansión del comercio necesariamente requiere regulación, y que es en la regulación de la competencia -y por tanto en la contención o no de la violencia- donde se encuentra el genio del sistema? 
Ahora bien, si uno hace a un lado la idea de acuerdo con la cual el modelo de regulación fue producido por occidente para ser luego copiado en otros lugares, estas dos cuestiones convergen sin mayores problemas. Pareciera que tal es la ruta del historiador Lauren Benton y otros, como Giovanni Arrighi, que se han dado a la tarea de corregir las mejores intuiciones de Gunder Frank (su firme anclaje en la cuestión de la innovación y la divergencia en términos de espacio y tiempo real) volviendo a la teorízación jurídica de Adam Smith por ejemplo, para situar la opción por la guerra y la expansión militarista en el camino que va del derecho como regulación de la competencia en los mercados, al derecho estado-céntrico, y de vuelta al modelo multicéntrico y la fusión entre seguridad y desarrollo a comienzos del siglo veintiuno. A estos y otros autores como Henri Lefevre y David Harvey, hay que considerarlos como verdaderos pioneros de algo así como un 'giro espacial' en filosofía política, teoría jurídica, y antropología histórica de los derechos. Propongo dar este giro, y propongo también que este giro es la clave para dar el paso de la teoría jurídica particular a una general, de la posibilidad de entender el derecho en perspectiva global, y para comprender mejor nuestra relación cambiante con la política y el gobierno desde la perspectiva del derecho en el sentido de las investigaciones iniciadas ya hace varias décadas por el historiador de las ideas Michel Foucault, entre otros.

En un sentido similar al de estos autores, puede afirmarse de manera provocativa que la pregunta correcta acerca de la producción y viaje del derecho y los derechos puede resultar muy parecida a aquella que postulase la llamada teoría de los trabajos del derecho de Karl Lewellyn: ¿Cómo es que el derecho devino estado-de-derecho? ¿Cómo es que la ley devino territorio, una forma concreta y particular que divide y por lo tanto realiza el universal, la forma del tiempo y el espacio? O de otra manera ¿cuál es la relación entre derecho, derechos, y gobierno de los hombres y las poblaciones asentadas sobre y desplazadas de la tierra mediante procesos militares y/o biopolíticos? (Foucault, 2001: 186 y ss; Twining, 2009: part I, 4; Fitzpatrick \& Golder, 2009).

Puesto el problema de esta manera la respuesta tiene que ver con lo que el historiador de las institutciones Lauren Benton llama the politics of legal ordering, y que he asociado aquí a la teoría de Lewellyn, como el proceso universalizable que explica la formación del derecho-estado, y su ocaso. El derecho-estado no solamente ha regulado los intercambios de propiedad sino que también ha establecido por la fuerza definiciones de propiedad y subjetividad, y como nos ha enseñado Michel Foucault, ha servido como la forma vacía que ocupan y en la cual se transforman la una en la otra, la acumulación de las reglas sobre propiedad y las identidades sociales y políticas en lucha. Además, tales reglas y tácticas nunca han operado de manera automática y libre de contra-poderes, que compiten por establecer verdaderas innovaciones y alternativas. La replicación u homotopía (este veritable allanamiento del espacio y el tiempo), que no la mera copia de las instituciones jurídico-políticas habría tenido lugar a través de la continua yuxtaposición de alternativas.

\section{REPLICANTES}

Para concluír: la homotopía político-jurídica, o 'replicación' -al contrario de la difusión- no es inevitable ni universal por sí sola. Entiéndase por 'replicación' el proceso de advenimiento al ser, en espacio y tiempo específicos, de formas y entes ius-políticos siempre contingentes y entre los cuales no puede distinguirse jerárquicamente en términos de original y copia. No se trata de un fenómeno universal pero sí es universalizable. Ello quiere decir que donde tiene lugar, ello se debe no a un 'entendimiento cultural', a convergencias naturales, formas unívocas de dependencia intelectual o a tendencias universales de la razón o el mercado, sino a las similitudes en la dinámica estructural de los conflictos que da lugar a ciertas expectativas compartidas.

El proceso de replicación es una forma de yuxtaposición y resonancia, antes que difusión viral, 
transplante, u otra metáfora médica. Valga notar además que este uso

del lenguaje médico a propósito de los fenómenos de expansión y descolonización territorial políticojurídica ha sido ligado por varios investigadores a la relación entre la extensión planetaria de las formas de desarrollo capital-mercantilista y la securitización y gobierno de los territorios y las poblaciones. ${ }^{9}$ Dicho proceso da lugar no a pluralidades legales que pueden convergir o no, sino a universos jurídico-políticos en lucha, que co-existen así no lo hagan de manera pacífica. Las similitudes o replicaciones políticas y jurídicas ciertamente facilitaron el proceso de colonización en la mayoría de lugares no porque producían orden por sí mismas sino porque generaron un marco -un espacio ordenado y orientado, supuestamente allanado- para el conflicto.

Esta es la lección que se deriva de comparar lugares en donde esta homología u homotopía tuvo lugar y lugares en las que no. De la falta de homología/topía no se sigue la disfuncionalidad y entonces la prevalencia terca del sistema 'tradicional', como afirma Brian Tamanaha (2001), sino la incapacidad por parte de los participantes de interpretar las políticas del otro en términos familiares que les permitiesen acomodar su conducta e instituciones para acomodar las diferencias. Se trata de la incapacidad de ponerse en el lugar del otro por medios otros que los puramente simbólicos o imaginarios, de generar terceros exteriores que permitan la comunicación indirecta, de amar a otros, por ejemplo, como dice el filósofo puertoriqueno Nelson Maldonado-Torres, al tiempo que se confronta juntos una situación homicida (Maldonado-Torres, 2008, 140).

De ahí la importancia de estudiar el papel de los intermediarios en los procesos de contagioresonancia. No porque los tales 'programen' a la multitud desde afuera, sino al contrario, porque su papel consiste precisamente en desaparecer, como Orestes o Ernesto Guevara, una vez los cuerpos resuenan como los puntos focales dispersos en el espacio y el tiempo en una pieza musical que sin embargo logran imponer el ritmo de sus propias vibraciones, con lo cual siempre adquieren mayor densidad, con el fin de mostrar que la distinción entre multitudes programadas desde fuera por un líder y multitudes sin líder no existe.

Quizás una lectura algo más caritativa de La Teoría Impura del Derecho de Diego López (2004), consista precisamente en mostrar como enfatiza, de manera correcta, el papel de los intermediarios culturales para luego afirmar que sus lecturas, malas o buenas, son de hecho lo que menos importa. Pero si ello es así, no es su creatividad contaminada y por ello mismo lineal a la hora de importar las modas foráneas lo que interesa (digo lineal en el sentido de la difusión, de lo que se expande de un lugar a otro tras una chispa incial, proceso que para él no puede ser tan solo prescrito o implicativo, sino también vivido como una experiencia singular). Lo interesante, y esto vale también para las modas, es que aparezcan y desaparezcan. Su forma es la de la música y no la de la formación de un canon literario, una plaga, una contaminación viral, o un fuego en el bosque. En tal sentido, la formación de redes a partir de la acción de actores intermediarios es muy parecida a la insurrección, la acción colectiva innovadora. Y entonces, es en el estudio (una forma de pensamiento activo) de estos eventos de insurrección donde se encunetran las claves para resolver las paradojas del constitutcionalismo y los derechos.

Para finalizar, el punto es el pánico que sigue a la desaparición del 'líder' o 'su idea', la forma paradójica de la unidad de la multitud que en ausencia del líder y su

programa, lo sustituye por el dogma (Supiot, 2007) como en la película La Batalla de Argel de Gillo Pontecorvo. En tal sentido, afirmo que toda constitución y declaración prescriptiva de derechos es dogmática. Y si ello no suena suficientemente progresista, recuérdese que todo dogma es en últimas parcial e indemostrable. Dicho de otra manera, el axioma del derecho es el siguiente: este dogma está fracturado, el centro del poder esta vacío; aprende a vivir sin dogma! Llamemos a esta, que propongo, la nueva teoría dogmática del derecho. 


\section{NOTAS}

${ }^{1}$ Aquí hay una referencia directa y crítica frente a los intentos re-eleccionistas de Ejecutivos fuertes en la región, como en los casos Colombiano y Venezolano, bastante más parecidos de lo que se cree a pesar de sus publicitadas diferencias. También a la 'continuidad' de formas de gobernancia de la población (en las favelas por ejemplo) que mantienen una zona de excepción más propia de la era dictatorial en el Brasil post-transición, y que algunos escritores Brasileros como Douglas Ferreira Barros han hecho patente. En tales casos, y sobre todo en el Colombiano, existe un claro proyecto de sustitución de la Constitución por la figura del Ejecutivo excepcional, que es parte de una metástasis de la política trans-nacional de securitización que afecta a todo el hemisferio, como en los casos recientes del ataque militar en territorio Ecuatoriano y las bases militares con presencia militar Estadounidense en territorio Colombiano, bajo la excusa de 'continuar' la lucha contra las drogas y el terrirismo, ambas, como bien se sabe en el resto del hemisferio, estrategias fallidas y corruptas.

${ }^{2}$ Acerca de la fabricación de seres y poblaciones 'monstruosas' unida al uso del catastrofismo que llamaré 'oscurantista', por oposición a uno más profético, liberador y esclarecedor, véase el magnífico trabajo de los Gordon, Jean y Lewis Ricardo, titulado Of Divine Warning (2009). Lewis R. Gordon es quizás el más influyente filosófo que haya emergido del caribe en los últimos años, y uno de los más importantes representantes de la fenomenología emparentada con el pragmatismo Americano en los Estados Unidos. Para una aclaración de su posición en relación con esta tradición, tan socorrida y como malentendida entre nosotros, véase su trabajo Disciplinary Decadence (2006).

${ }^{3}$ Lo importante aquí es, de una parte, no confundir la objetividad de las ciencias más duras con la pretensión de última palabra que es propia de la ly en derecho, y de otra parte, prestar atención a las hibridizaciones entre la objetividad científica y el juicio jurídico indiferente cuyo objeto es mantener la estabilidad del edificio tecno-temporal de 'archivos' jurídicos y político-jurídicos. Cuando se habla de la objetividad de una encuesta para sustentar la capacidad y validez representativa de un actor político constituído o elegido por la constituyencia, se acude precisamente a la confusión entre objetividad de laboratorio y la pretensión de palabra última que debería evitarse para comprender mejor la voluntad de estabilidad y seguridad del aparato de fabricación jurídica. Los 'hechos' del lenguaje jurídico-político son 'factoides', entonces, en el sentido de esta confusión y la cautela anti-metafísica que informa el evitar que esa confusión agote la actividad y significado de las operaciones jurídico-políticas. Estas últimas, a fin de cuentas, se preocupan por la estabilidad del sistema heterønomo (la tal 'seguridad jurídica') precisamente como síntoma y reconocimiento de su fragilidad y contingencia vis-à-vis las capacidades autónomas humanas asociadas en común y en el Común (la 'cosa' y la 'Cosa' o Das Ding, para usar la etimología que recupera Latour). Véase Latour, B. (2004: Cap. 4).

${ }^{4}$ Para una crítica relacionada pero diferente del difusionismo 'ingenuo' en derecho comparado y perspectivas globales acerca de los derechos humanos, repito muy cercana pero algo más moderada que la presentada en este ensayo, véase Twining (2009: 269-293).

${ }^{5}$ Para un examen de la relación entre estos pragmatismos metafísicos (en la medida en que suponen una permanencia originaria que se sostiene en los cambios y las crisis), y que hay que distinguir del pragmatismo no metafísico ni utilitarista de un William James, y los modelos de securitización en finanzas y política, véase Guardiola-Rivera (2009a: Capítulos 8-10).

${ }^{6}$ Véase De Sousa Santos (2009).

${ }^{7}$ Véase el muy lúcido esfuerzo antropológico-histórico de Juan Felipe García (2009) acerca de la emergencia del penalismo en Colombia, Véase también el excelente trabajo desarrollado por Ricardo Sanín sobre criticismo constitucional (2009).

${ }^{8}$ Véanse Fanon, 1968, 40; Maldonado-Torres, 2008, 140; Guardiola-Rivera, 2009a, Cap. 10, y, 2009b, 2-4. 
${ }^{9}$ Véanse los trabajos de J. F. García (2009) para el caso Colombiano en América Latina, y de Mark Duffield para el caso de las 'nuevas guerras' en Europa y Oriente Medio. Ambos apuntan a la manera en que los procesos de securitización de poblaciones y territorios tienden a formular sus justificaciones en lenguajes cercanos a los de la medicalización y la higiene: el neo-humanitarianismo contemporáneo, afirma Duffield, 'contiene' los riesgos y mueve los nuevos ejércitos humanitarios y las ONG's asociadas a ellos a través del planeta como si fuesen unidades de descontaminación. García muestra la presencia de estos lenguajes pseudo-racionales (i. e. higiene, salud pública, determinancia ambiental, raza, etc.) en los procesos de establecimiento del derecho penal y de reforma constitucional en el siglo XIX Colombiano (apropiadamente presentada en términos de 'regeneración y catástrofe). Véase García (2009) y Duffield (2007). Antes que meros préstamos o re-localizaciones orgánicas de un cuerpo (político) a otro, investigaciones como las de Duffield y García sugieren que el contexto apropiado para comprender los paralelismos institucionales, políticos y jurídicos en diversos lugares del globo es el de la guerra, la toma de la tierra, el establecimiento de líneas divisorias, orden y orientación, es decir, todo aquello respecto de lo cual el jurista Alemán Carl Schmitt hablaba al recuperar un cierto sentido del término ley como nomos.

\section{BIBLIOGRAFIA}

Abélès, M. (2008) Política de la Supervivencia. Buenos Aires: Eudeba.

Comité Invisible, El. (2009) The Coming Insurrection. Los Angeles: Semiotext(e).

Escobar, A. (2008) Territories of Difference: Place, Movements, Life, Redes. Durham: Duke University Press.

Duffiel, M. (2007) Development, Security, and Unending War. Governing the World of Peoples. London: Polity Press.

Fanon, F. (1968) The Wretched of the Earth. New York: Grove Press.

García J. F. (2009) Regeneración o Catástrofe. La Formación del Orden Penal en el Siglo XIX en Colombia. Bogotá: Fondo Editorial Javeriano.

Gordon, L. R. (2006) Disciplinary Decadence. Living Thought in Trying Times. Boulder \& London: Paradigm.

Gordon, J. \& Gordon L. R. (2009) Of Divine Warning. Reading Disaster in the Modern Age. Boulder \& London: Paradigm.

Guardiola-Rivera, O. (2009a) Being Against the World: Rebellion and Constitution. London: Routledge/Birkbeck Law Press. (2009b) 'Further reflections on violence: A response to Simon Critchley', en Naked Punch: Engaged Review of Contemporary Art \& Thought. Issue 12, Agosto/Septiembre. London \& Lahore: NP Collective, 2-4.

(2010) What If Latin America Ruled the World? London \& New York: Bloomsbury.

López-Medina, D. (2004) Teoría Impura del Derecho: La Transformación de la Cultura Jurídica Latinoamericana. Bogotá \& Miami: Legis.

Maldonado-Torres, N. (2008) Against War: Views from the Underside of Modernity. Durham: Duke University Press.

Sanín, R. (2009) Teoría Crítica Constitucional. Salvando la Democracia del Liberalismo. Bogotá \& Buenos Aires: Abeledo Perrot/ Universidad Javeriana.

Sousa Santos, B. De (2009) 'Por que é que Cuba se transformou num problema difícil para a Esquerda?', en Encarte CLACSO-Cadernos de América Latina, X. Enero de 2009. Buenos Aires \& Sao Paulo: CLACSO.

Stengers, I. (2009) 'William James: An ethics of thought?', en Radical Philosophy 157, Septiembre/Octubre, 2009. London: Russell Press/RP, 9-19. 
Supiot, A. (2007) Homo Juridicus: On the Anthropological Function of the Law. Londres: Verso. Original en Francés: [2005] Homo juiridicus. Essai sur la function anthropologique du droit. Paris: Seuil.

Tamanaha, B. (2001) A General Jurisprudence of Law \& Society. Oxford: Oxford University Press.

Twining, W. (2009) General Jurisprudence. Understanding Law from a Global Perspective. Cambridge: Cambridge University Press. 